\title{
Potential of InSAR monitoring for seismic areas in Romanian
}

\author{
Mihaela Gheorghe ${ }^{1,2}$, Iuliana Armaș ${ }^{1}$, Eduard-Ilie Năstase ${ }^{2}$, \\ Alexandra Munteanu ${ }^{2}$ \\ ${ }^{1}$ Center for Risk Studies, Space Modeling and Dynamics of Terrestrial and Coastal Systems, \\ University of Bucharest, Faculty of Geography \\ ${ }^{2}$ National Institute of Earth Physics, Măgurele, Ilfov
}

\begin{abstract}
National Institute of Earth Physics operates one of the densest real-time regional networks in Eastern Europe for monitoring seismic activity, counting 130 real time seismic station and 22 permanent GNSS stations. The network serves for early warning applications, research studies regarding seismic sources and internal Earth structure, as well as crustal deformation monitoring. In areas that make the object of detailed studies for crustal deformation, additional periodic GNSS stations are installed in monthly surveying campaigns, increasing the coverage of the network.

The current study focuses on two regions of interest, Izvoarele-Galați and Black Sea coast, monitored with 9 and 4 GNSS reference points respectively. The Izvoarele-Galați represents an interesting research site because of recent abnormal seismic behaviour, while the Black Sea coast is integrated in a project for a regional early-warning system for marine geohazards. Satellite synthetic aperture radar interferometry is proposed as a complementary monitoring technique that can offer insights regarding surface deformation in addition to information offered by classic techniques such as GNSS and optical levelling.
\end{abstract}

Keywords: InSAR, earthquake, Permanent Scatterer, Dobrogea, Galați

\section{INTRODUCTION}

Since the launch of the European Remote Sensing (ERS) 1 satellite in 1991, radar remote sensing has become very popular in studies that are based on surface displacement and deformation monitoring. Although relatively new in comparison to classic monitoring techniques such as optical levelling or GNSS, InSAR (Interferometric Synthetic Aperture Radar) has been preferred in many studies instead of classic techniques due to the possibility to cover large areas in a short amount of time and at lower costs, accessibility to remote areas and offering a high density of measured points with comparable accuracy results.

InSAR has been used in various studies, from earthquake epicentre or fault slip identification and modelling (Massonnet et al., 1993; Fialko et al., 2005, Wright et al., 2001), geological or tectonic subsidence and uplift monitoring in built-up areas (Cigna et al.,
2011; Armaș et al., 2017), identification of subsidence due to underground constructions or gas extraction (Perissin et al., 2011) or slow developing landslides monitoring (Ye et al., 2004).

Satellite InSAR is based on pairing two SAR satellite images acquired at different times over the same area and in the same geometry in order to obtain interferograms. Interferograms contain information regarding phase variation of the signal in the line of sight (LOS) of the sensor between two different acquisition in the same geometry.

First time when InSAR was used for depicting earthquake related surface deformation was in 1993, when Massonnet et al., 1993 studied a 6.9 magnitude and 1.09 depth earthquake that took place in Landers, California. By processing two satellite images taken by ERS-1 before and after the event, the scientists depicted $0.6 \mathrm{~m}$ displacements kilometres away from the epicentre. Since then, InSAR has contributed to increasing substantially 
the number of modelled earthquakes, from only 15 before 1993 to 30 in the last 25 years. However, all the earthquakes that were studied with the help of InSAR techniques have occurred at a maximum depth of $30 \mathrm{~km}$, therefore being considered shallowdepth earthquakes.

The first studies involving satellite InSAR were analysing single pairs of images to determine changes that occurred in an area between two acquisition dates, usualy before and after an event took place. Ferretti et al., 1999 and Berardino et al. 2002 have proposed algorithms for multi-temporal InSAR techniques, like Permanent Scatterer (PS) and Small BAseline Subset (SBAS) InSAR in order to monitor fine displacements of the earth surface. These techniques improve the results precision from centimetres to millimetres. Ferretti et al., 1999 proposed a multi-temporal approach that allows exploiting sets of multiple interferograms selected from large image sequences acquired over longer periods of times for the same area. A single SAR satellite image from the actual sensors can cover areas of $10000 \mathrm{~km}^{2}$ or wider with a frequency of a few days (6 days for Sentinel-1A and B). Therefore, data about phenomena can be obtained before, during, and after their occurrence, resulting in monitoring time series.

The technique proposed is the Permanent Scatterer technique (PS). The PS was used and improved for a multitude of applications that required displacement times series monitoring. The basic principle of the PS technique is that radar sensors can observe ground surface objects whose reflectance remains coherent in time, backscattering radar radiation for as long as their displacements are smaller than half the wavelength of the signal. The objects that are reflective to microwaves are mainly represented by objects from the built-up areas, such as buildings, infrastructure, poles or bridges, or open rocks from natural sites.

The advantage of studying very small displacement rates from multiple acquisition has been exploited for approaching earthquakes by studying possible earthquake precursors depicted as low magnitude surface deformations. Earthquake precursors can consist of unusual surface movement patters, such as atypical subsidence or uplift phenomena in areas near the earthquake epicenter
(Moro et al., 2017). Starting with 3 years before the earthquake that occurred in L'Aquilla, Italy, a subsidence of $15 \mathrm{~mm} / \mathrm{yr}$ has been found above quaternary basins in the proximity of the epicentre. After the earthquake, the same surface was characterized by a continuous uplift of $12 \mathrm{~mm} / \mathrm{yr}$.

In the current paper, we present the results obtained after processing Sentinel-1A data using the PS technique for monitoring two areas of interest for their seimsic behaviour, the Izvoarele-Galați area and the Black Sea coast, in an attempt to identify fine surface movements that characterize the surface of the study sites and can be used for seismic and geological interpretations.

\section{STUDY AREA}

One of the important objectives of the National Institute for Earth Physics (NIEP) is to detect and locate in the shortest all seimsic events (anthropic, natural) occurences. The information can be used in an early warning system addressed to authorities, emergency situation personel and the wide public. Part of the monitoring network that has been developed by the NIEP is represented by the Romanian high resolution GNSS / GPS (Global Navigation Satellite System / Global Positioning System) networks designed for monitoring crustal movements, started in 2001 when the first permanent station was installed in Lacauti.

Although the seismic hazard in Romania is dominated mainly by intermediat-depth seismicity characteristic to the Vrancea zone, there are also areas where shallow-depth earthquakes occur and have been offered a particular interest in time.

\section{- Izvoarele-Galați area}

Starting in September 2013, a swarm of more than 500 earthquakes occurred over an interval of 3 months in an area found $30 \mathrm{~km}$ from Galați, in the South-Eastern foredeep. A swarm is represented by a multitude of low magnitude earthquakes. Earthquake swarms occur also in other areas of Romania, such as the Carpathian Bend or the Sinaia region However, the 0.1-4 magnitude earthquakes on the Richter scale that occurred in the Izvoarele-Galați area were considered atypical due to their longer duration and higher intensity in comparison to other areas. 
The area was investigated by specialists from many different fields, like geologists, surveyors and earth physicists, in an attempt to find an explanation for the surface movement patterns (Năstase et al., 2016; Ioane et al., 2015). The Negrea village area where the seismic swarm emerged and the Izvoarele village where the effects of earthquakes are amplified are differentiated. The hypothesis is that some local effects in the Izvoarele area might influence the surface behaviour. The local effects have been classified as terrain conditions and geological conditions.

According to the geology experts, the Izvoarele Slobozia Conachi localties from the Galați area are located over predominantly unconsolidated (sand and gravel) deposits (Micu, 2017). One interpretation of the earthquake swarm is based on mechanical suffusion processes that cause changes in the surface area and precede the event (geological conditions). Another hypothesis for the causes that may influence the magnitude and duration the earthquakes was anthropic intervention: the extraction of gas and oil for more than 30 years in the area. Due to exploitation on the three domes of the Petrolum Structure Independence platform on which the localities are found, the land can suffer differential compaction (terrain conditions).

Immediately after the events, NIEP has installed portable seismic GNSS equipment to mark GNSS reference points. Six GNSS reference points were added to the already existing 3 permanent monitoring stations found in the area. The purpose of GNSS monitoring was determining crustal deformation rates and displacement directions close to the affected areas [11].

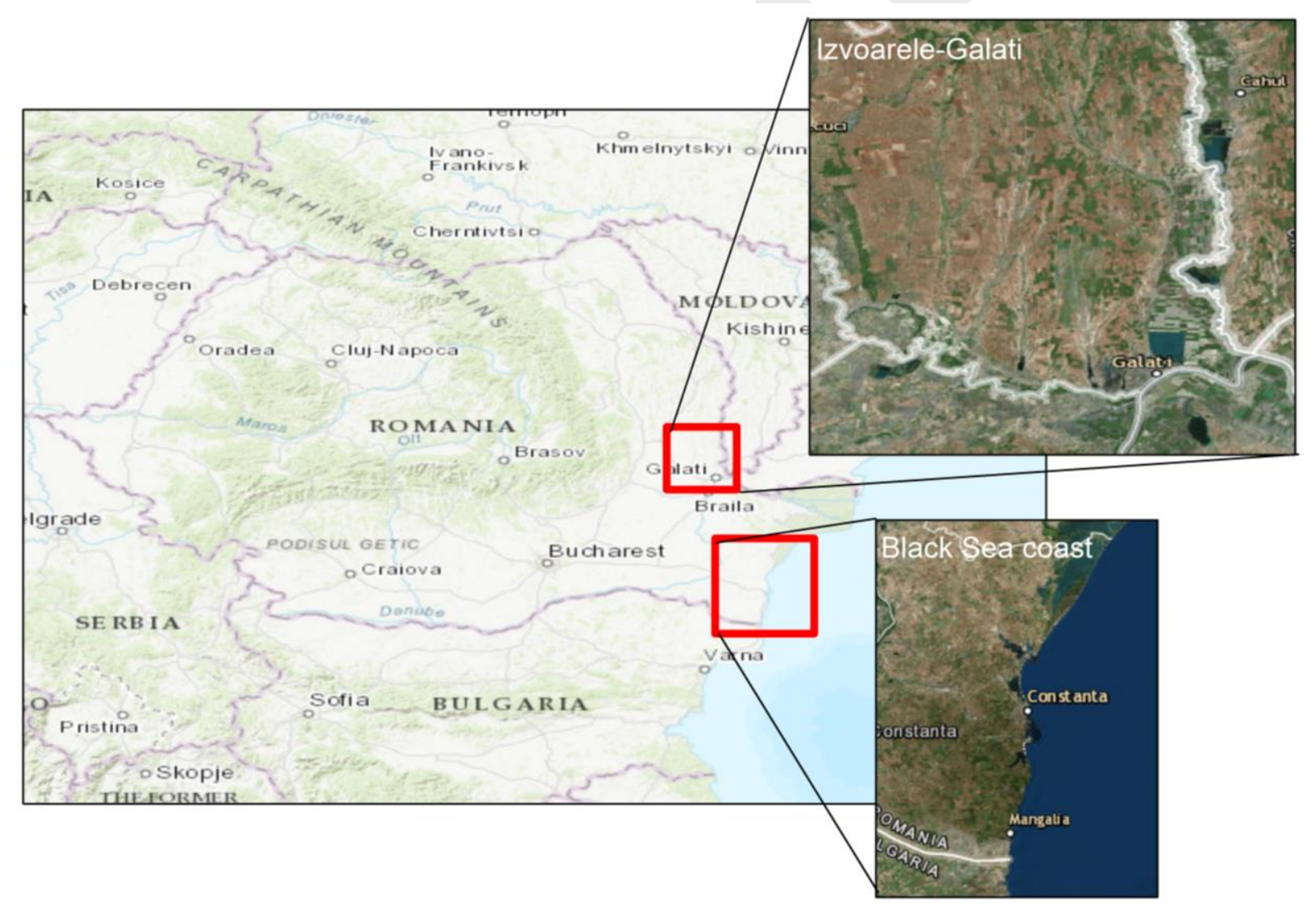

Figure 1 Localization of Izvoarele-Galați and Black Sea coast study areas in Romania

\section{- Black Sea coast}

The seismic hazards in the area of Dobrogea are characterized by shallow earthquakes $(0-10 \mathrm{~km})$ (Bala et al., 2013). The foci of shallow earthquakes can be divided into three areas (western part of
North Dobrogea, east of Tulcea and the SE of Central and NW of South Dobrogea), with the seismic hazard derived from shallow earthquakes being higher in South Dobrogea, controlled by the events in the Shabla region. Besides the crustal 
movement on the Black Sea Coast, the Black Sea area is also liable to tsunamis generation. Although the last tsunami that was observed in the Shabla region was dated on $31^{\text {st }}$ of March, 1901, statistics show that more than 20 tsunamis have been observed in the past in the area. The oldest recorded tsunami that has been recorded on the Romanian shore is dated back in year 104. The shallow depth of the earthquakes in the area, of around $15 \mathrm{~km}$ below the sea, can result in tsunami waves of $5 \mathrm{~m}$ height and material losses.

The NIEP are studying extreme marine events and catalogue marine geohazards. The main purpose of establishing a monitoring network on the Black Sea coast was create an early warning system for marine hazards in the Black Sea. In this respect, NIEP has developed a coastal network for marine seismicity, by installing seismic stations, Sea Level Sensors, Radar and Pressure sensors, Meteorological and GNSS stations at every site in the coastal area of the Black Sea. The GNSS stations of interest are installed in Constanța, Mangalia and Sulina localities.

\section{METHODOLOGY}

One of the most recent SAR satellites are Sentinel1A and Sentinel-1B, launched by the European Space Agency in 2014 and 2016 respectively. The signal wavelength of the Sentinel-1 satellites is approximately $5.6 \mathrm{~cm}$ (C-band). The individual temporal resolution of each satellite is of 11 days. Because it is recommended to use images from a single satellite for interferometry studies, and due to its longer acquisition time, we have chosen to process and analyse the Sentinel-1A data. The Sentinel-1A images were made available by the European Space Agency for free (ESA) through the Copernicus program, and were downloaded from https://scihub. copernicus.eu/dhus after creating an account.

The first sensing time of the Sentinel-1A images is dated back in 2014, exactly after the events in the Galați area occurred. Images were downloaded and processed using the PS routine implemented in Sarscape v. 5.2 software provided by SARMAP.

In the Black Sea area, the GNSS permanent stations and reference points are found in built-up areas. The satellite images were processed for
Constanța, Mangalia and Sulina cities for the 2015-2017 - time interval. A number of 54 Sentinel-1A on descending orbit were processed for Galați area for the interval between 06.03.201510.08.2017 [Fig. 2]. For Constanţa and Sulina, 29 images in descending orbit sensed between 13.05.2015 and 23.09.2017 were downloaded and processed [Fig. 3]. For comparison with Mangalia 1 and 2 permanent stations, 27 images in descending orbit were acquired [Fig. 4].

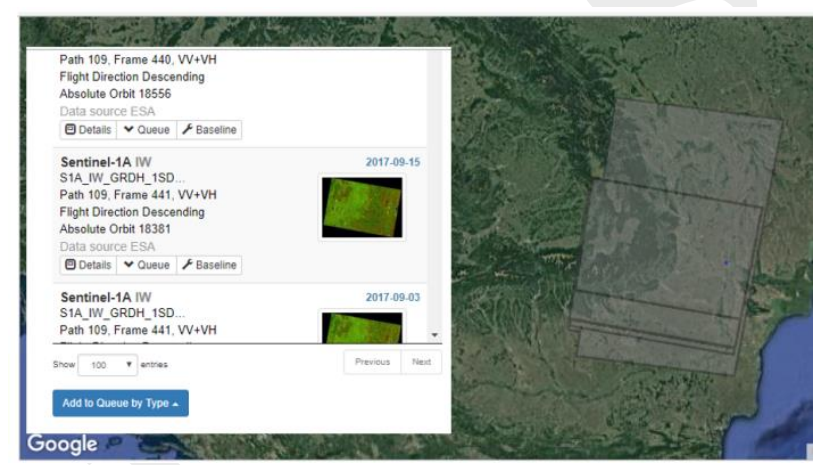

Figure 2 Extent of the Sentinel-1A images for IzvoareleGalați area

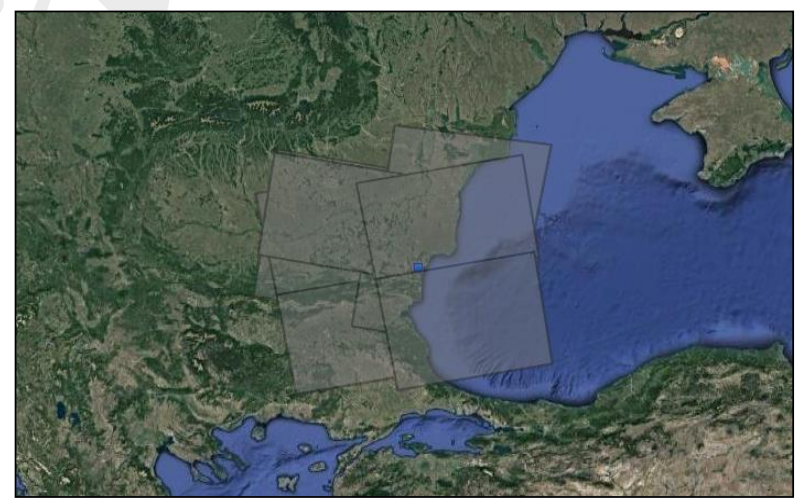

Figure 3 Extent of the Sentinel-1A images for Constanța and Sulina

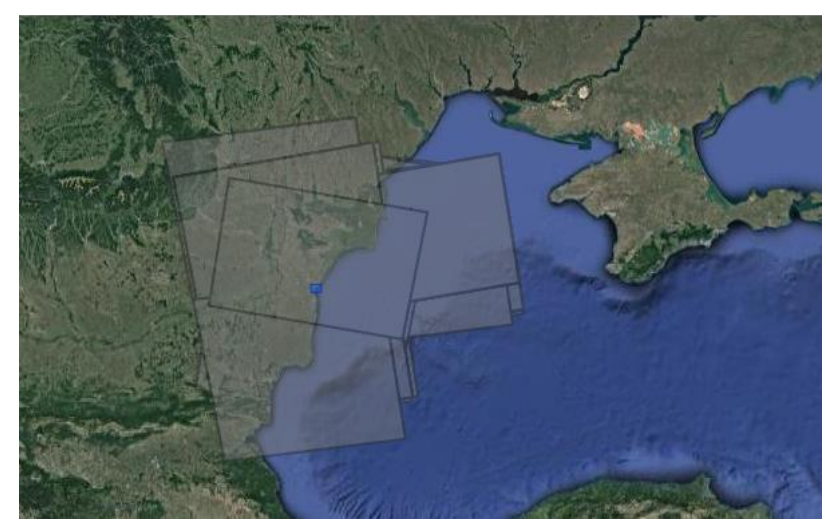

Figure 4 Extent of the Sentinel-1A images for Mangalia 
The main objects that are identified using the PS processing algorithm are man-made objects, such as buildings and infrastructure. In the Galați-Izvoarele area, some of the GNSS reference points were installed outside the built-up areas, therefore, couldn't be compared to PS results.

Firstly, the PS algorithm identifies the permanent reflector candidates by selecting those with higher amplitude dispersion values. Height errors are then eliminated using an external digital elevation model (DEM), the Shuttle Radar Topography Mission (SRTM) (90 m resolution and $16 \mathrm{~m}$ vertical accuracy) in this case. The atmospheric errors were eliminated using a low pass and a high pass filter for spatial and temporal corrections. In the end, the annual displacement rates as well as displacement values were calculated for all existent permanent scatterers and displayed as discrete points showing cumulated displacement values and velocity rates.

Between 2015 and 2017, the Sentinel-1A satellite acquired images of the Galați area every 11 days, summing up to a number of approximately 70 images. From these images, 54 images containing the study area and ranging from 06.03.2015 until 10.08.2017 were selected for surface motion monitoring. In order to diminish the influence of the atmosphere, images that were acquired during heavy precipitations, earth snow cover, overcast or foggy weather conditions, were eliminated before

The resulted points, corresponding to each coherent point identified, were georeferenced in the WGS 84 system and displayed as a deformation map of the studied areas.

The movement tendencies of each GNSS point was compared to the movement patterns depicted for points found within $50 \mathrm{~m}$ from each GNSS station. In the Izvoarele-Galați area, besides the already existing three permanent stations, and additional 6 stations were installed and measured periodically between 2014 and 2015, when three surveying campaigns were conducted in the area. After 2015, the surveying campaigns continued at random time intervals, whenever traveling in the study area was possible.

In Constanţa, Mangalia and Sulina, there are installed 1, 2 and 1 permanent stations respectively in the built up areas. For each monitored point, a displacement tendency and displacement rate value were depicted. In Fig. 5, the vertical surface movements resulted for the period between 2013 and 2017 are represented as vectors. The movement tendencies for the GNSS point stations in the study area were interpreted as uplift or subsidence.

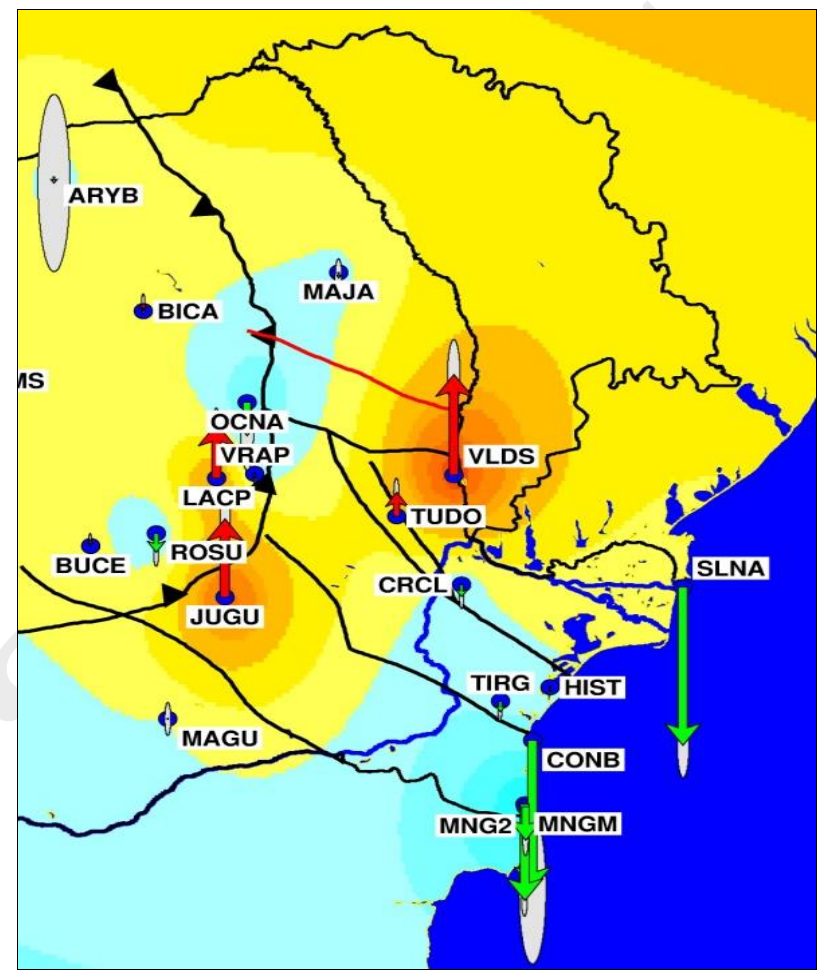

Figure 5 GNSS derived vectors for the study areas

\section{RESULTS}

For the Izvoarele-Galați study area, we have obtained 176887 points with velocity values ranging from $-28 \mathrm{~mm} / \mathrm{yr}$ to $20 \mathrm{~mm} / \mathrm{yr}$ with an accuracy of $\pm 0.5 \mathrm{~mm}$. Velocity values characterizing the Galați area have a normal distribution, with a higher frequency of the values between $-3.0 \mathrm{~mm}$ and $+3.0 \mathrm{~mm}$ [Fig. 6].

The southern part of the study area is characterized by an uplift pattern with velocity values between $0.6 \mathrm{~mm} / \mathrm{yr}$ up to $5 \mathrm{~mm} / \mathrm{yr}$, resulting in a cumulated displacement value of $+14 \mathrm{~mm}$ in 2 years. The high uplift values are high especially along the Siret river terrace, which is bordering the study area. The velocity and displacement values are higher than the average displacement rates that are characterizing the area. 


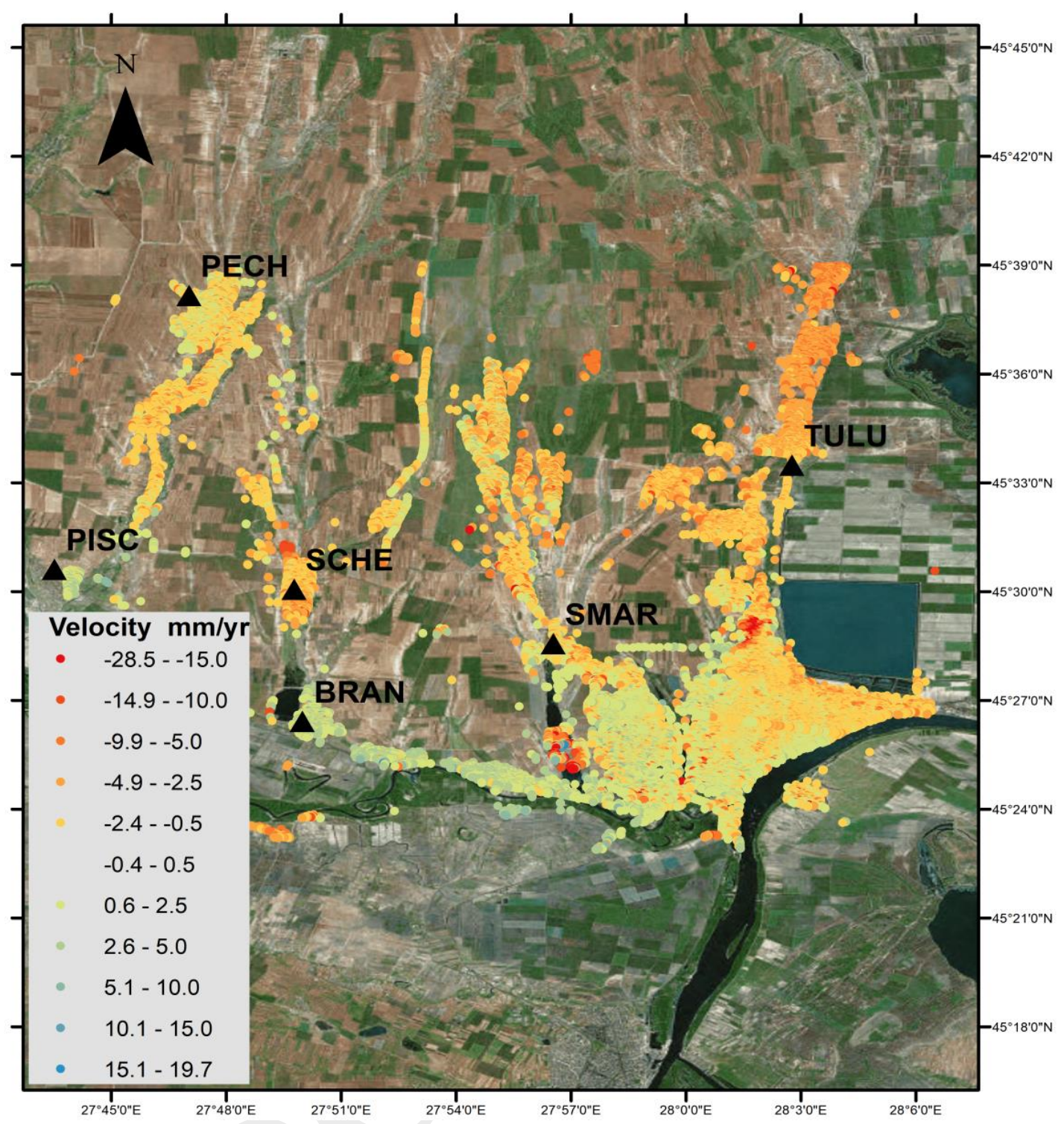

Figure 6 Deformation map obtained for the Galati-Izvoarele area

An interesting pattern of local very high subsidence values was obtained for 3 areas in the study area, found on the gas and petroleum extraction platform. These localized subsidence regions are of the order of hundreds of square meters. Their average velocity values range from $5 \mathrm{~mm} / \mathrm{yr}$ to $-10 \mathrm{~mm} / \mathrm{yr}$, reaching cumulated displacement values of around $-30 \mathrm{~mm}$ in two years [Fig. 7]. Due to their limited area and very high displacement values, these affected areas can be considered as compaction sites caused by human intervention during extraction activities.

On the Black Sea coast, we have obtained 184067 points for Constanța, 67803 points in
Mangalia and 16798 points in Sulina. The average velocity values range from $-24 \mathrm{~mm} / \mathrm{yr}$ to $24 \mathrm{~mm} / \mathrm{yr}$ for Constanța [Fig. 8], and smaller intervals for Mangalia and Sulina, between $-19 \mathrm{~mm} / \mathrm{yr}$ and $13 \mathrm{~mm} / \mathrm{yr}$ [Fig. 9, 10]. The surface movement evolution depicted for Constanța shows mainly stability, affected also by noise. In Mangalia, besides the general surface movement patterns that show stability, we have obtained also a strip of subsiding points along the road that links the northern part of the locality to the southern part. This motorway is subsiding with more than $5 \mathrm{~mm} / \mathrm{yr}$, its points reaching on average $-15 \mathrm{~mm}$ cumulated displacement values in two years. 


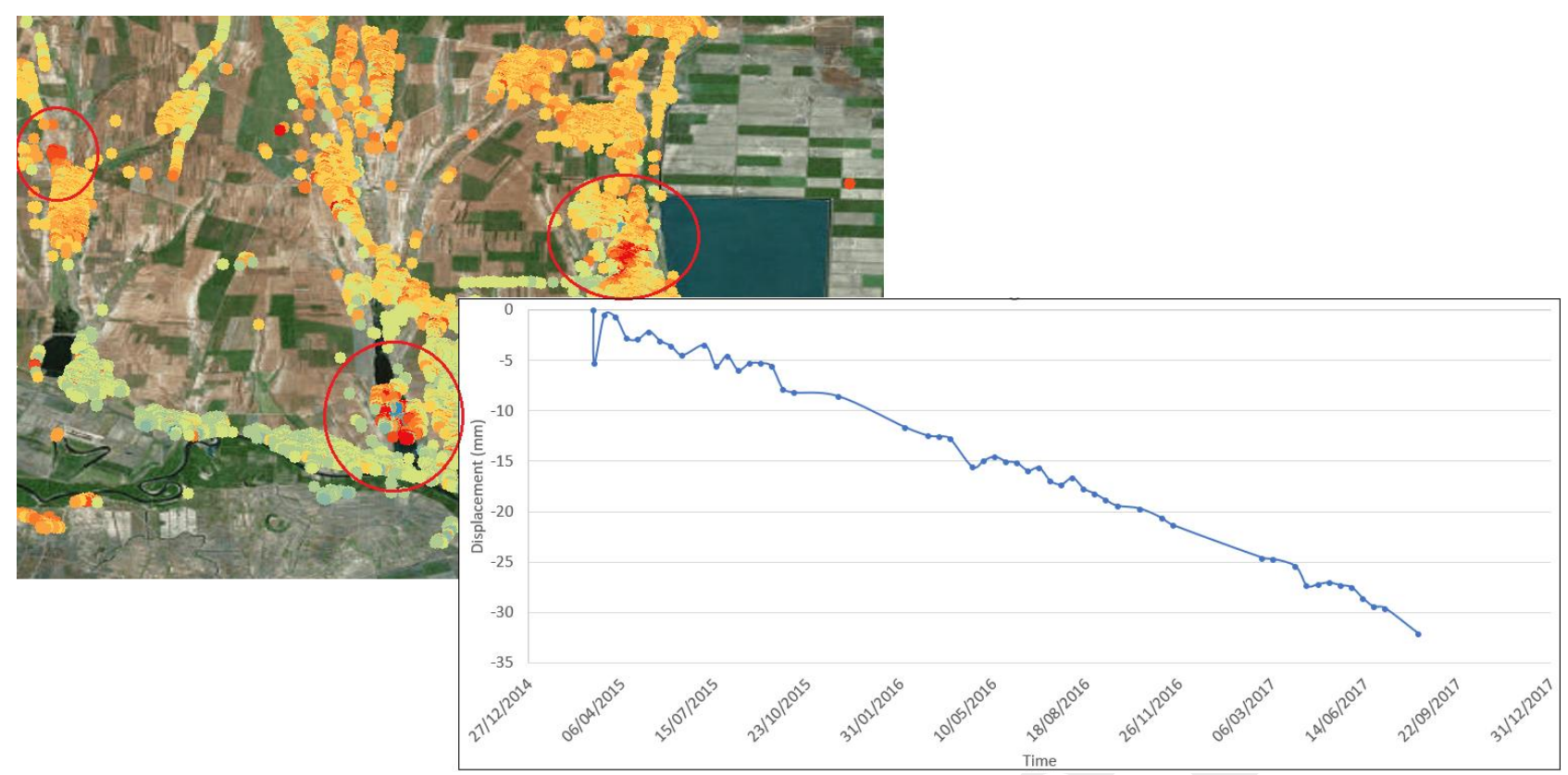

Figure 7 Compaction zones in Galați and Izvoarele characterized by cumulated displacements of - $35 \mathrm{~mm} / \mathrm{yr}$

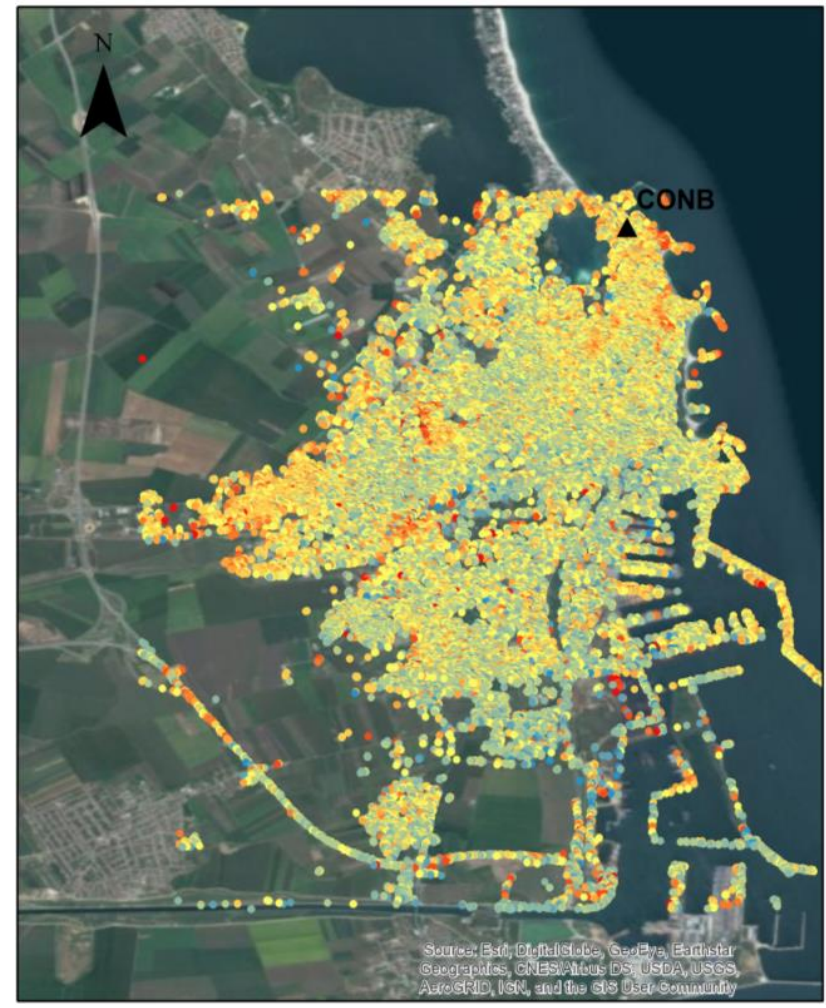

Figure 8 Deformation map obtained for Constanța

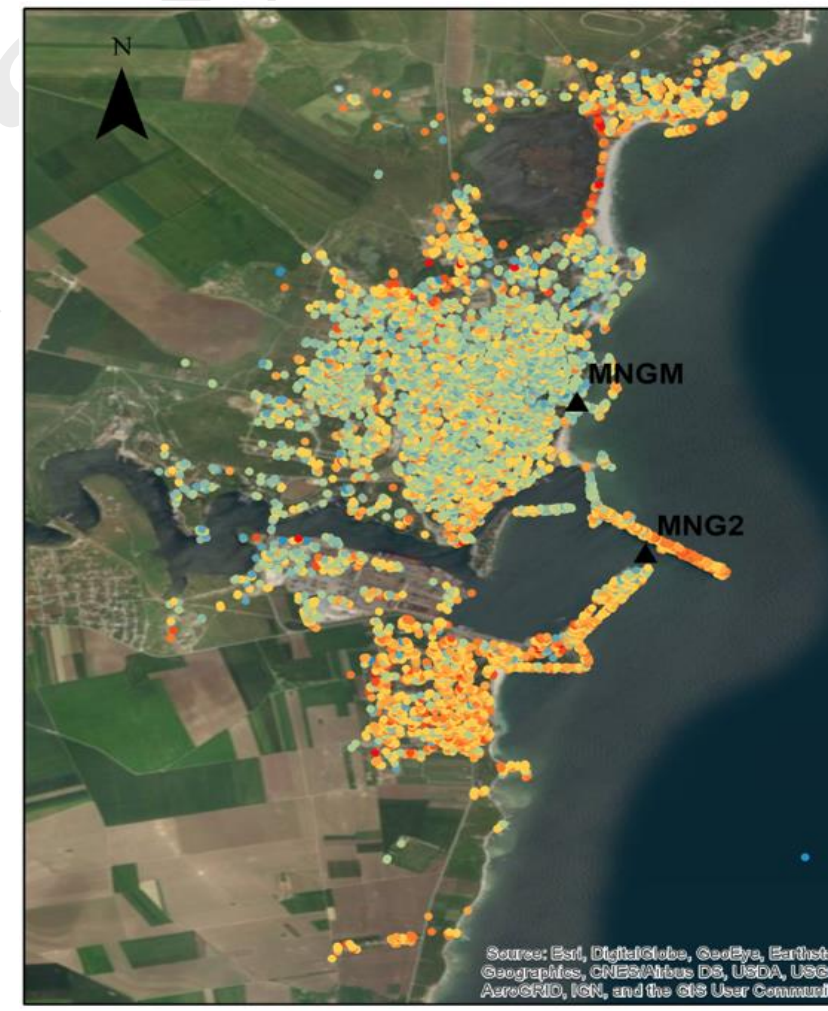

Figure 9 Deformation map obtained for Mangalia 


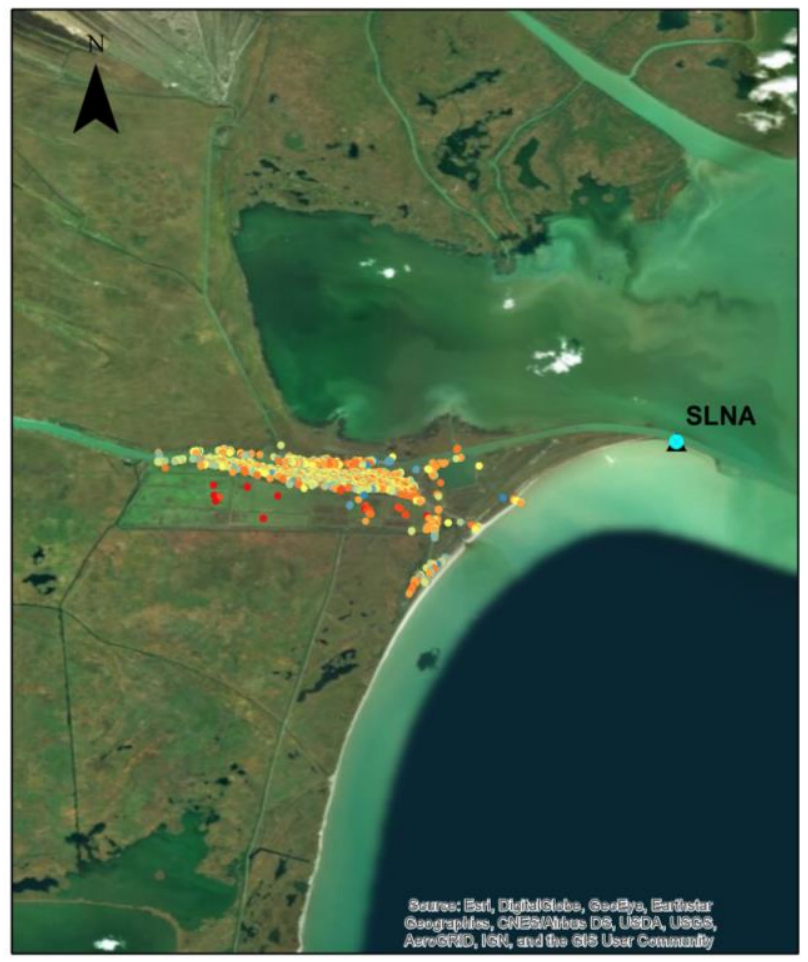

Figure 10 Deformation map obtained for Sulina

Table 2 Comparison between GNSS derived displacement tendency and PS-InSAR results

\begin{tabular}{|c|c|c|c|}
\hline \multirow{2}{*}{$\begin{array}{c}\text { GNSS } \\
\text { station }\end{array}$} & \multicolumn{2}{|c|}{ Displacement tendency } & \multirow{2}{*}{ Correspondence } \\
\cline { 2 - 3 } & $\boldsymbol{G N S \boldsymbol { S }}$ & $\boldsymbol{I n S A \boldsymbol { R }}$ & \\
\hline PECH & Uplift & Uplift & Yes \\
\hline TULU & Uplift & Subsidence & No \\
\hline PISC & Subsidence & Uplift & No \\
\hline SCHE & Subsidence & Subsidence & Yes \\
\hline SMAR & Subsidence & Subsidence & Yes \\
\hline BRAN & Uplift & Uplift & Yes \\
\hline SLNA & Subsidence & Subsidence & Yes \\
\hline CONB & Subsidence & Subsidence & Yes \\
\hline MNGM & Subsidence & Stability & No \\
\hline MNG2 & Subsidence & Stability & No \\
\hline
\end{tabular}

\section{CONCLUSION}

The main scope of our research was obtaining preliminary results from multitemporal InSAR techniques, such as PS processing of Sentinel-1A data. The areas of interest were represented by Galați-Izvoarele and Black Sea coast, which are both interesting sites from the point of view of seismic behaviour.

The deformation maps describing the areas show displacement rate values between $-28 \mathrm{~mm} / \mathrm{yr}$ and 20 $\mathrm{mm} / \mathrm{yr}$ for Galați, between $-24 \mathrm{~mm} / \mathrm{yr}$ to $24 \mathrm{~mm} / \mathrm{yr}$ in Constanța, and smaller interval ranges for Sulina and Mangalia.

The general subsidence pattern in Izvoarele Galați could be explained by a tectonic subsidence that is characterizing the whole study area. The subsidence along the riverbed of Siret could be attributed to the continuous deposition of sand and gravel sediments. The localized high subsidence values are associated to human interaction which is causing differential land compaction through gas and petroleum extractions.

Besides the subsiding motorway in Mangalia, the coastal localities are characterized by stability patterns and seasonality.

In what concerns the comparison against the GNSS results, not all the compared movement patterns were characterized by a good agreement. The main reason that we considered was the difference in time table between the GNSS and InSAR acquisitions. There were also GNSS reference points that were not compared to PS results because they were installed outside the builtup area, and no permanent reflectors were depicted in their proximity.

Although the deformation map obtained for the current study was linked to both geological and human interaction in the area, we consider that the results require a more thorough investigation from a geological perspective. Due to the suggestive patterns that we identified in the deformation maps, that could not be depicted through GNSS monitoring, InSAR proves to be a valuable monitoring tool that can bring additional information and complete discrete GNSS data.

\section{REFERENCES}

Massonnet, D., Rossi, M., Carmona, C., Adragna, F., Peltzer, G., Feigl, K., \& Rabaute, T. (1993). The displacement field of the Landers earthquake mapped by radar interferometry. Nature, 364(6433), 138.

Fialko, Y., Sandwell, D., Simons, M., \& Rosen, P. (2005). Three-dimensional deformation caused by the Bam, Iran, earthquake and the origin of shallow slip deficit. Nature, 435(7040), 295.

Wright, T., Fielding, E., \& Parsons, B. (2001). Triggered slip: observations of the 17 August 1999 Izmit (Turkey) earthquake using radar interferometry. Geophysical Research Letters, 28(6), 1079-1082. 
Cigna, F., Del Ventisette, C., Liguori, V., \& Casagli, N. (2011). Advanced radar-interpretation of InSAR time series for mapping and characterization of geological processes. Natural Hazards and Earth System Sciences, 11(3), 865.

Armaş, I., Mendes, D. A., Popa, R. G., Gheorghe, M., \& Popovici, D. (2017). Long-term ground deformation patterns of Bucharest using multi-temporal InSAR and multivariate dynamic analyses: a possible transpressional system?. Scientific Reports, 7, 43762.

Perissin, D., Wang, Z., \& Wang, T. (2011). The SARPROZ InSAR tool for urban subsidence/ manmade structure stability monitoring in China. Proceedings of the ISRSE, Sidney, Australia, 1015.

Ye, X., Kaufmann, H., \& Guo, X. F. (2004). Landslide monitoring in the Three Gorges area using D-InSAR and corner reflectors. Photogrammetric Engineering \& Remote Sensing, 70(10), 1167-1172.

Ferretti, A., Prati, C., \& Rocca, F. (1999). Permanent scatterers in SAR interferometry. In Geoscience and Remote Sensing Symposium, 1999. IGARSS'99 Proceedings. IEEE 1999 International (Vol. 3, pp. 1528-1530). IEEE.

Berardino, P., Fornaro, G., Lanari, R., \& Sansosti, E. (2002). A new algorithm for surface deformation monitoring based on small baseline differential SAR interferograms. IEEE Transactions on Geoscience and Remote Sensing, 40(11), 2375-2383.

Moro, M., Saroli, M., Stramondo, S., Bignami, C., Albano, M., Falcucci, E., ... \& Macerola, L. (2017). New insights into earthquake precursors from InSAR. Scientific Reports, 7(1), 12035.

Nastase, E. I., Muntean, A., Toma-Danila, D., Mocanu, V., \& Ionescu, C. (2016). Study Of Nw Galati Seismogenic Area, 3 Gps Campaigns From 2013 2015, Preliminary Results. International Multidisciplinary Scientific GeoConference: SGEM: Surveying Geology \& mining Ecology Management, 3, 631-638.

Ioane, E. D., Serban, P. D. A., Diaconescu, P. D. E. M., \& Chitea, L. D. E. F. (2015). High Seismicity Sequence In The Izvoarele Area (Galati County)Romania.Proceedings of 15th International Multidisciplinary scientific geoconference, SGEM, 1043-1051.

Micu, M. (2017). The systematic of landslide processes in the conditions of Romania's Relief. In Landform Dynamics and Evolution in Romania (pp. 249-269). Springer, Cham.

Bala, A., Radulian, M., \& Popescu, E. (2003). Earthquakes distribution and their focal mechanism in correlation with the active tectonic zones of Romania. Journal of Geodynamics, 36(1-2), 129-145. 